\title{
X-ray tomographic microscopy tightens affinity of the early Cambrian Oymurania to the brachiopod stem group
}

Artem Kouchinsky and Stefan Bengtson

Acta Palaeontologica Polonica 62 (1), 2017: 39-43 doi:https://doi.org/10.4202/app.00320.2016

The geologically rapid biotic evolution in the early Cambrian is marked by the first appearance of major groups of animals in the fossil record (e.g., Budd and Jensen 2000; Kouchinsky et al. 2012). Along with the earliest crown-group representatives of the phylum Brachiopoda, more basal branches of the phylogenetic tree belonging to the stem-group Brachiopoda, such as tannuolinids and mikwitziids, diversified and became widespread during the early Cambrian (e.g., Williams and Holmer 2002; Balthasar et al. 2009; Skovsted et al. 2014). Synchrotron-radiation X-ray tomographic microscopy (SRXTM) of Oymurania gravestocki reveals the microstructure of its calcium-phosphatic shell differentiated into two layers and intersecting systems of canals. The outer layer shows the acrotretoid columnar microstructure and the inner layer consists of continuous prismatic columns. Phosphatized setae preserved within tangential canals, as well as perpendicular canals of Micrina-Setatella type demonstrate homology with the tannuolinid Micrina and the mickwitziid Setatella. A unique and novel combination of microstructural features in Oymurania confirms its evolutionary position within the brachiopod stem group.

Artem Kouchinsky [artem.kouchinsky@nrm.se] and Stefan Bengtson [ㅎtefan.bengtson@nrm.se], Department of Palaeobiology, Swedish Museum of Natural History, Box 50007, SE-104 05 Stockholm, Sweden.

This is an open-access article distributed under the terms of the Creative Commons Attribution License (for details please see creativecommons.org), which permits unrestricted use, distribution, and reproduction in any medium, provided the original author and source are credited. 
PaF Supplementary file $(809.8 \mathrm{kB})$ 